\title{
Housing ownership among female migrants in South Africa: The case of metropolitan and non-metropolitan areas.
}

\author{
Philomene Nsengiyumva and Gabriel Tati \\ Department of Statistics and Population Studies, \\ University of the Western Cape, South Africa. \\ pnsengiyumva@uwc.ac.za
}

\begin{abstract}
In the study of female migration and housing acquisition, little has been elaborated about the magnitude and the direction of female migrants in South African context. Furthermore, housing tenure status is still under researched. Hence, the determinants of housing ownership, and how this differs across metropolitan and non-metropolitan areas is not sufficiently documented in migration and housing literature. This paper aims at identifying the factors contributing towards housing ownership among internal female migrants, and the differentials in comparing metropolitan and non-metropolitan areas in South Africa. This study makes use of the 2007 Community Survey data requested from Statistics South Africa. Logistic regression analysis was performed to highlight the relationship between female migration and housing ownership across areas. The key findings indicate that age, duration of residence, housing type, and household size are the factors contributing towards housing ownership among female migrants. The study found, further, that female migrants living in non-metropolitan areas are more likely to own housing in relation to metropolitan areas.
\end{abstract}

Key words: Migration; housing ownership; Statistic South Africa

\section{Introduction}

The feminization of migration is a topic that has been prominently visible in literature. The participation of women in migration worldwide is not something recent (Fawcett et al, 19 Tati, 2010). In the context of South Africa, women are not exempted from migration behaviour (Groenmeyer, 2010). They are migrating as much as their male counterpart to certain areas of South Africa, for different reasons, including housing acquisition (Obaid, 2006). During apartheid era, women in general and wives in particular were prohibited from migrating to stay with their husbands or other male kin in cities. It is only after the dawn of democracy in 1994, women who had been left behind by their husbands to keep the fire at home burning now started moving freely around the country just like their male counterparts (Obaid, 2006; Cross et al, 2008). This new migration stream, however, creates tension in housing sector, especially in large cities. The main defect is housing ownership among female migrants living in metropolitan areas, where since the onset of democracy in 1994, it became difficult for women migrants to own a place to stay in. While there is a long debate on access to scarce resources in internal female migration literature (Fisher and Jaffe, 2003; Miraftab, 2003), female migration and access to housing is silent in migration research. The accurate information on housing ownership is rare and scanty in the context of South Africa.

The general objective of this study was to answer a research question "what are the factors contributing towards housing ownership among female migrants across areas of residence". This paper seeks to link migration and housing, by examining the empirical determinants of housing ownership among female migrants in South Africa. The aim of this study, therefore, was to provide a national overview of the magnitude and the direction of internal female migration; housing tenure status in general and specifically, housing ownership. More so, this study specifically contributed to the growing body of knowledge on women migration and housing ownership.

\section{Literature review}

Based on the census of 1996 and 200I, Gardner (2004) and Rust (2006) found that about half of South African households live in some kind of accommodation that they own, including traditional, private dwelling units, ex-council stock and subsidised housing units. Maharaj, (20I2) notes that over a third of South African households live in accommodation that they rent, including private rentals, social housing facilities, council rentals and the informal settlements rentals. The rest of the South African residents are 
known to be squatting in the informal settlements dwelling units (Gardner, 2004, Rust, 2006). For female migrants, however, depending on their profiles, they often try and locate themselves in these different kinds of shelters, such as shack settlement areas, rented accommodation, formal owned housing type and government subsidy type of housing schemes (Cross, 2008).

Gardner (2004) provides a nuanced perspective of the housing tenure and housing conditions of different households in South Africa. The study shows that over $50 \%$ of South African households own their dwelling units. Another $35 \%$ of South African households rent their housing accommodation while $12 \%$ of the households squat in informal settlement housing and live in informal housing conditions; and this is the housing reality for the female migrants choose from (Charlton, 2004; Gardner, 2004; Rust, 2006; Maharaj, 20I2). Literary evidence suggests that income earnings, assets and relative housing prices are important factors affecting housing tenure changes (Ingram, 1997). In addition, there is also an assumption that changes in migrants' economic circumstances such as prices, inflation and increased mortgage rates can also affect female migrants' housing tenure choices (Huang and Clark, 2002). Thus, it can again be hypothesized that home ownership may increase with individual's household income earnings.

Since housing prices are lower at the periphery of large cities than in inner cities, large households are often more decentralised, living in medium or smaller towns and cities where large households may be accommodated more easily in owned accommodation, different from what would be possible when living in rented dwellings in metropolitan areas. It is in these circumstances that, generally, large households are often found in smaller towns generally found in non-metropolitan municipalities areas (Udjo, 20I5).

Home ownership in metropolitan areas is becoming generally and increasingly unaffordable to the poor and unfeasible to women migrants heading households especially those who are living in metropolitan municipality areas (White Paper, 1994). According to the Department of Housing White Paper: A New Housing Policy and Strategy in South Africa, this skewed housing tenure system can possibly be attributed to the old South African legacy of racial, spatial and geographical separation that has created vast distortions in settlements patterns, leading to an uneven distribution of municipal capacity, particularly between urban and rural municipalities (White Paper, 1994). More so, highly educated female migrants, with a good and wellpaying employment; with a decent monthly income http://aps.journals.ac.za earning is all that is required to boost the potential of female migrants to own a house in metropolitan areas.

\section{Conceptual framework}

There is no specific theory that could be used to explain female migration and housing ownership in the South African context. Some theories elaborating on migration were revised and used as a starting point to conceptualize a framework which could serve as a background for this study. The theoretical line of inquiry followed in this study is deterministic, emphasizing selectivity and differentials in migration and housing ownership. Along this line, migration selectivity is one type of theory of migration that is reviewed in this study and which links migration and housing. It has been observed in the human migration literature that not all migration follows a random process (Swart, 2004). This means that migrants do not always reflect a random sample of the population from which they came (Feliciano, 2005; (Schnaiberg, 1970; Kok, 1986; Curran and Rivero-Fuents, 2003). Lee (1966) argues that migration is selective with respect to the individual migrant's characteristics since people respond differently to 'plus' (positive) and 'minus' (negative) factors at the place of origin and place of destination. Migration selectivity means that migrants have the characteristics differ with the non-migrants.

Research on migration and selectivity uses explanatory or predictor variables such as age, gender, marital status, educational level, career and life cycle, to name a few (see Shaw, 1976) to predict housing ownership. Indeed, the selective nature of migration by a considerable body of demographic and sociological research has focused primary on variables listed above. However, a question remains is a theoretical point of view way in which migration selectivity operates under specific conditions. Bogue (196I) cited in Shaw (1976) referred to this as specified contribution of environmental conditions at places of origin and destinations. The argument developed in this study concerning the latter, stipulated that the selectivity and differentials operate in conjunction with the counter-selectivity of destinations to which migrants move to. In other words, inasmuch as migration select individuals at areas of origin according to certain characteristics, the areas of destination exert in counterpart, a selectivity in inserting migrants in their opportunity structure. This means all scarce resources available in the places of destination. This may be particularly the case for housing ownership. Opportunity structure including housing acquisition differs according to the layer onto which the area is located within the national settlement system. The stock of housing 
depends on the population size and function of the areas within the national settlement system. The decision to be made by the individual female migrant with respect to housing tenancy status may vary not only because of those variables listed above, and others related to the individual, but also because of the housing situation prevailing in the areas of destination. In the context of this study, the area of interest is metropolitan and non-metropolitan municipalities of South Africa where it is assumed that housing ownership is still problematic for people in general and female migrants in particular. On the basis of this conceptual framework, the present study brings together the ideas from different sources of literature about migrants' characteristics on selectivity as a way of trying to understand what accounts for age, gender, level of education, population group, marital status, province of birth and province of previous residence, duration of residence, household headship, household size, housing type and housing ownership across the different areas of residence in the context of South Africa. However, it seems that using the migrant characteristics selectivity, one can still borrow from this theory to establish a relationship between female migrants' characteristics and housing ownership across metropolitan and non-metropolitan municipality areas.

\section{Data sources and methods}

This study used the 2007 Community Survey data requested from Statistics South Africa. The community Survey is a nationally representative, large-scale household survey which was conducted from February to March 2007. The community Survey is designed to provide information on the trends and levels of demographic and socio-economic data including access to facilities and services (Statistics South Africa, 2008).

After the evaluation of the data by the Statistics Council, the Community Survey was found to be comparable in many aspects with other Statistics South African surveys, censuses and other external sources. It was released to the users on $24^{\text {th }}$ October 2007. The 2007 Community Survey data is a reliable data because it is produced by an institution with a high quality surveys and censuses. The sampling method is very efficient with a sample size highly representative which can be easily generalized to the entire population (Statistics South Africa, 2008).

With regards to data collection, the 2007 Community Survey (CS) was collected by Statistics South Africa. The Community Survey questionnaire (individual and household questionnaire) was the main tool used to collect the data from the households of sampled dwelling units. The sampling 3273 procedure adopted by Statistics South Africa for the survey was a two-stage stratified random sampling process. Since the data was required for each local municipality, each municipality was considered as an explicit stratum. The first stage was the selection of EAs (Enumeration Areas) within each municipality. The EAs within each municipality were ordered by geographic type and EA type. The selection of EAs was done using a simple systematic random procedure. The only constraint measure considered all EAs in municipalities selected. In all those municipalities with 30 EAs or more, the sample selection used a fixed proportion of 19\% (Statistics South Africa, 2008). The second stage of the sample design involved the selection of dwelling units. The selection of dwelling units was based on a fixed proportion of $10 \%$ of the total listed dwellings in EAs. For the CS, enumerators allocated by Statistics South Africa visited the selected sampled dwelling units to interview households.

Looking at the data collection procedure, enumerators visited the selected sampled dwelling units to interview households. The respondent to the questionnaire was the head or the acting head of the household. However, if the head or acting head was not around the oldest responsible household member acted as the respondent. The respondent was not supposed to be younger than 15 years of age. In exceptional circumstances, however, a person younger than 15 years would be considered the respondent if it was found that there was no older household member alive or living with them (Statistics South Africa, 2008).

\section{Variables and definition}

This study used independent variables and dependent variables to test a hypothesis linking migration and housing. With regard to independent variables in this study, the paper used socio-demographic variables, socio-economic variables, migratory variables, household variable, and housing variable. The dependent variable was "Owned and fully paid housing". Looking at independent variables, sociodemographic variables refer to age, gender, marital status, level of education. Socio-economic variables refer to employment status, occupation, and income. Migratory variables refer to province of birth, province of previous residence, and duration of residence. Household variables refer to household size. Housing variables refer to housing structure type, and housing ownership.

Some new variables were computed, especially when variables were nominal or ordinal with more than three categories. For example, the dependent variable "Owned and fully paid" was dichotomized in SPSS and it became (I) = Owned and fully paid; (0) 
$=$ other methods. The dependent variables such as province of birth or province of previous residence had nine categories. When these variables were transformed, they were given only three categories computed as: $(I)=$ Urbanized province; $(2)=$ not urbanized province; (3) = Outside RSA. Income category became: $(I)=$ Low income; $(2)=$ Medium income; (3) $=$ High income. Variable level of education became: (I) = Primary; (2) = Secondary; (3) = Degrees; (4) No schooling. Continuous variable with long list of categories such as age, duration of residence, household size were automatically categorized by SPSS when computing logistic regression. To perform the logistic regression, the reference categories were automatically computed in SPSS. The default was the "highest coded" last category. For population group as an example, ( 1 ) = Black, (2) = Coloured, (3) = Asian/Indian, (4) $=$ White. Since this variable is categorical, SPSS indicated a reference group with the highest coded last category as 'White'.

\section{Statistical analysis}

Given that the dataset had three different files, those separate files were converted into a rectangular file, so that every individual in the household could have information on housing. The information of household was replicated to the individual level in order to describe the housing situation for each and every female migrant in the household. The data were first summarised in tables and graphs. The magnitude and the main direction of female migrants were computed. The fixed-term net migration (the distribution of female migrants according to province of previous residence and province of current residence) and lifetime net migration (the distribution of female migrants according to province of birth and province of current residence) were produced from the data. The distributions of housing tenure status of female migrants in metropolitan and in nonmetropolitan areas were produced in figures. Furthermore, the distribution of each housing tenure status across metropolitan municipalities was performed.

Hence, the relationship between migratory variables, individual variables, household variables, socio-economic variables, and housing ownership variable was examined. By dealing with the factors which increase the chances of living in owned and fully paid, logistic regression analysis was used to determine those chances in terms of probability. A model which combines more than two variables was created, and the independent variables were simultaneously included in the model. This method helped to identify which independent variables were statistically significant with dependent variable. http://aps.journals.ac.za
Hosmer-Lemeshow goodness of fit informed us how closely the observed and predicted probabilities match. In this case a $p>0.05$ indicated that the model fit the data. In addition, $5 \%$ was used as cut off point as a level of significance. If Hosmer-Lemeshow goodness-of-fit test statistics is greater than 0.05 , as we want for well-fitting models, this implies that the model's estimates fit the data at an acceptable level. That well-fitting model shows non-significance on the H.L goodness-of-fit test. This desirable outcome of non-significance indicates that the model prediction does not significantly differ from the observed.

\section{Findings}

Sample description

According to the 2007 Community Survey, the distribution of female migrants according to the province of previous residence shows that the gross migration of female migrants across the nine provinces of South Africa was 54274. This figure represents all moves of all female migrants within a specific definition of migration as applied to this study. Net-migration was also calculated and shown in Table I. According to the United Nations, net migration refers to the balance of migration that happened in opposite directions (United Nations, 1970). In order to calculate net female migration from the 2007 Community Survey data, life-time and fixed-term migration data were used. Knowing that female migrants can be sub-divided into two migration streams on the basis of place of birth and on a fixed period (five year period) according to the place of current residence, the number of female migrants enumerated from each province of previous residence was cross-tabulated with their province of usual residence in 2005.

Using the distribution patterns obtained by crosstabulating province of previous residence and province of usual residence, a matrix balance was calculated first before producing net migration. The data depicted in tablel provides fixed-term net migration results. It indicates that the Western Cape, Northern Cape, Free State and Gauteng provinces gained more in-migrants than out-migrants hence; the reason for their positive net migrant output is high economic opportunities characterizing these provinces. This means that those provinces are highly attractive to people, and this can put pressure on some of the scarce resources in those provinces, including housing. Conversely, Eastern Cape, Kwazulu-Natal, North West, Mpumalanga and Limpopo, the number of out-migrants was higher than the in-migrants. This is the reason why net migration had a negative output. The meaning of this is that people tend to move out of these provinces than those who move in. 
Table I: Fixed-term net migration

\begin{tabular}{|c|c|c|c|}
\hline Province & $\begin{array}{l}\text { Fixed-term In- } \\
\text { migrants }\end{array}$ & $\begin{array}{l}\text { Fixed-term Out- } \\
\text { migrants }\end{array}$ & Fixed-term Net migrants \\
\hline Western Cape & 1405 & 639 & 766 \\
\hline Eastern Cape & 493 & 2155 & -1662 \\
\hline Northern Cape & 747 & 308 & 439 \\
\hline Free States & 1030 & 704 & 326 \\
\hline Kwazulu-Natal & 861 & 1129 & -268 \\
\hline Northern West & 891 & $124 \mid$ & -2509 \\
\hline Gauteng & 4219 & 1710 & 2509 \\
\hline Mpumalanga & 885 & 964 & -79 \\
\hline Limpopo & 492 & 1794 & -1302 \\
\hline
\end{tabular}

Source: The author's own calculation

\section{Life-time net migration}

With regard to life-time net migration, the calculation procedures are the same as that for fixed-term net migration. Table 2 shows that Western Cape, Northern Cape, and Gauteng provinces are the major destinations for female migrants in South Africa. In these provinces, the in-migrants outnumbered the out-migrants and this is the reason why the net migration balances give a positive outlook. Actually, these provinces received more female migrants than what they sent out, and this might eventually create tension in these provinces as places of destination that need resources to cater for the influx of new migrants. Looking at Western Cape, Northern Cape, and Gauteng Provinces, the number of in-migrants is higher than that of out-migrants. However, for Eastern Cape, Free State, KwazuluNatal, Northern West, Mpumalanga and Limpopo Provinces, the out-migrants out-number the inmigrants. One reason that might be that those provinces in the latter category tend to loose people more than what they receive because of fewer economic opportunities, especially wage differentials between these provinces. This ultimately results in female migration to places where economic opportunities are higher.

Table 2: Life-time net migration

\begin{tabular}{|l|l|l|l|}
\hline Province of Previous Residence & $\begin{array}{l}\text { Life-time In- } \\
\text { migrants }\end{array}$ & Life-time Out-migrants & Life-time Net migrants \\
\hline Western Cape & 3172 & 663 & 2509 \\
\hline Eastern Cape & 644 & 4884 & -4240 \\
\hline Northern Cape & 821 & 669 & 152 \\
\hline Free States & 637 & 1418 & -78 I \\
\hline KwaZulu-Natal & 1229 & 2076 & -847 \\
\hline Northern West & 1222 & 1873 & $-65 I$ \\
\hline Gauteng & 8726 & 127 & 8599 \\
\hline Mpumalanga & 1158 & 1472 & -314 \\
\hline Limpopo & 561 & 3288 & -2727 \\
\hline
\end{tabular}

Source: Author's own calculation

Housing tenure status of female migrants in metropolitan areas

This section looks at how housing tenure is distributed among female migrants across metropolitan and areas. As depicted in Fig.l, this study shows that majority of female migrants living in metropolitan are more likely to stay in rented dwellings (35.0\%). Those who live in owned but not fully paid dwellings and those who live in owned and fully paid housing accounted for almost similar proportions of $23.0 \%$ and $24.0 \%$ respectively. 


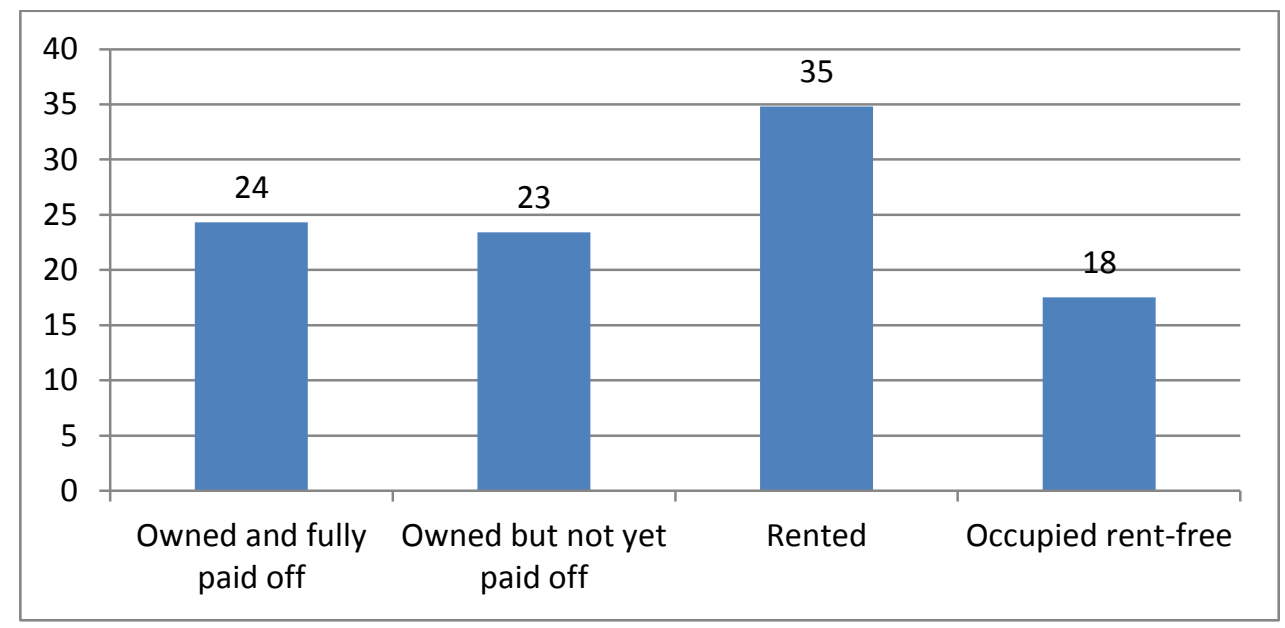

Figure 1: The distributions of housing tenure in metropolitan areas

Housing tenure status of female migrants in nonmetropolitan areas

As shown in Fig 2, the study discovered that majority of female migrants living in non-metropolitan areas were staying in owned and fully paid off dwellings $(42.0 \%)$. As most of them live in owned and fully paid housing, it might be the case of them using the selfhelp procedure to build their own housing. More so, for those who are eligible for RDP housing, they mostly get subsidized housing from the government. This is conclusive evidence that most governments in developing countries attempted, at one time or another, to house a portion of their population in one way or another. This is followed by those who were renting (28.0\%). However, the proportion of female migrants living in free accommodation was higher $(21.0 \%)$ than those staying in owned but not yet fully paid dwellings $(10.0 \%)$. This is controversial to metropolitan areas where the majority is living in rented dwelling due to a high density population and high life standard. Density means number of persons per square kilometre (Ingram, 1998). Hence, it can be concluded that residential density declines with distance from metropolitan to non-metropolitan areas, and this influences housing tenure status.

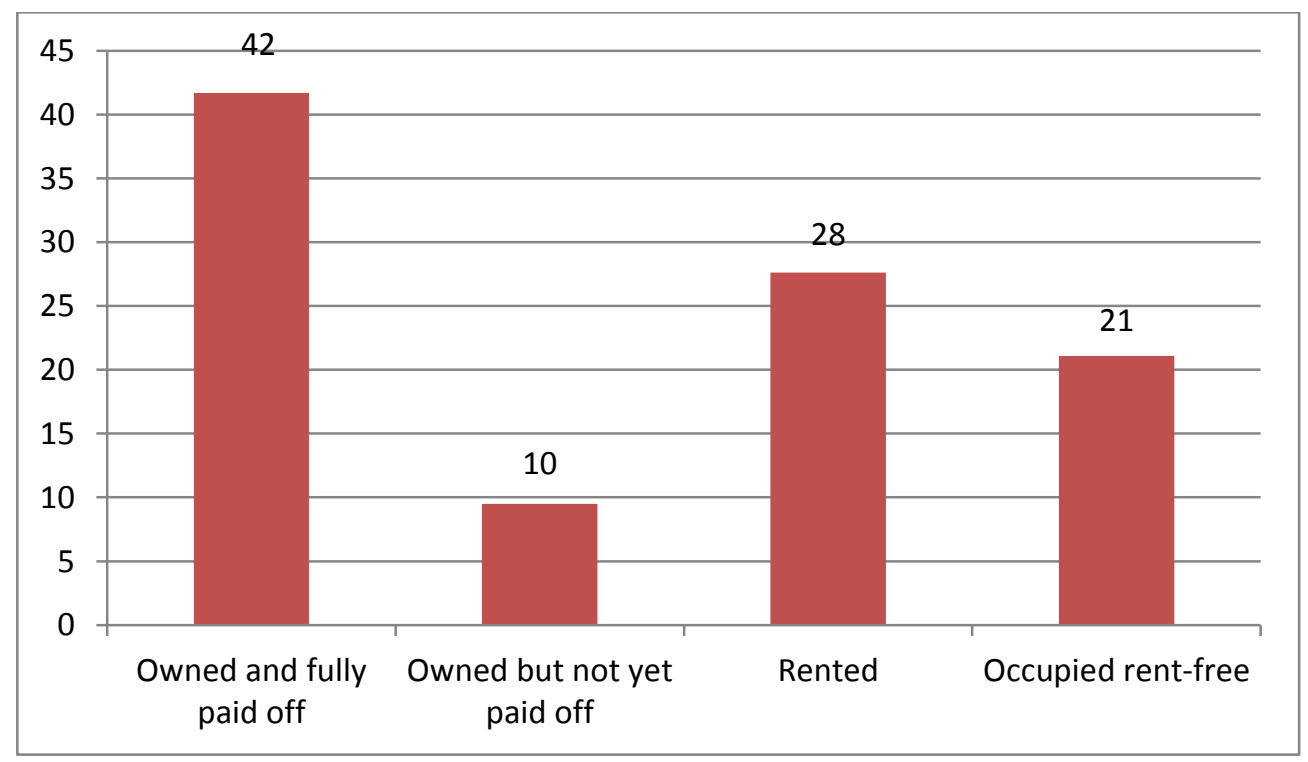

Figure 2: The distribution of housing tenure status in non-metropolitan area.

Housing acquisition among female migrants across metropolitan areas

Looking at Figure 3 below, the findings show that majority of female migrants heading households living in city of Tshwane live in rented dwellings (4I.6\%). In Nelson Mandela Metropolitan, a high proportion of http://aps.journals.ac.za female migrants heading household was highly represented in owned and fully paid dwellings $(50.9 \%)$. However, this proportion is higher compared to those female migrants not heading households in the same metropolitan municipalities. Like their counterparts not heading households, 
female migrants heading households living in EThekwini, Ekurhuleni, City of Cape Town, and City of Johannesburg were mainly living in rented dwellings $(39.6 \%, 44.1 \%, 42.4 \%$ and $42.4 \%$ respectively). These major cities are growing very rapidly and have a sustained influx of new in-migrants. Furthermore, research shows that Gauteng constitutes $4.8 \%$ per annum. The reason might be the high economic opportunities which continue to attract many migrants in metropolitan municipalities (Cross, 2008). Therefore, it is obvious that this high migration which flows into these metropolitan areas has a serious implication on services delivery especially on housing which affects seriously the poor including female migrants.

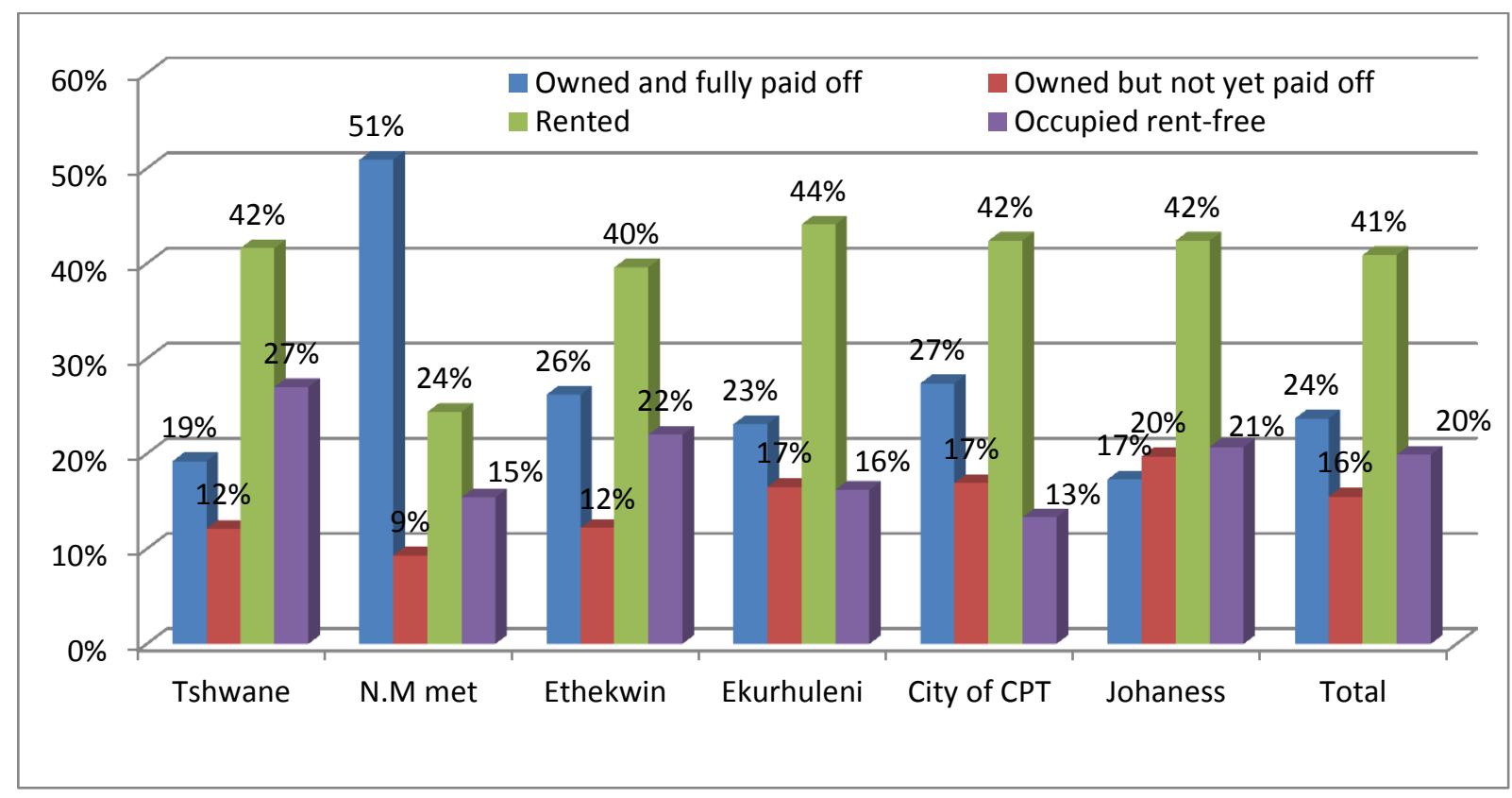

Fig 3: Distribution of housing tenure status across metropolitans

Factors contributing towards housing ownership among female migrants in metropolitan

Table 3 below reveal that an omnibus test of model coefficients was significant with $p=0.00<0.05$ and, -2 log likelihood showed that the data fits the model. The data further shows that an increment in age by one year results in an increase of the potential to own a fully paid up house by a factor of I.015. Hence, these results indicate that in metropolitan areas, the likelihood of owning a fully paid up house is influenced by the age of the female migrants. Therefore, it is worth noting that the older the female migrant, the more chances she has of owning fully paid housing unit.

Looking at housing structure type, the findings indicate that standalone housing type increases the chances of one having a fully owned housing unit in metropolitan areas by 2.943 times higher than floating housing in metropolitan areas. The reason for this, according to the 2008 report from the 2007 Community Survey is that the proportion of standalone housing had increased, such that buying a standalone housing unit was cheaper and more convenient than buying flats. Actually, many people prefer to buy free standing housing units than flats or floating dwelling units, especially when they have big families.

This study also shows that being low-income female migrants heading households living in metropolitan areas increases the chances of living in owned and fully paid housing unit by $1.75 \mathrm{I}$ times higher than having high income. The reason is that, for female migrants heading households with low income and living in major cities, there are many housing initiatives which encourage them to have access to housing ownership. The findings from this study also show that being employer female migrants does not necessarily entitle them to full housing ownership. It rather contributes fewer chances due to vulnerability among female migrants living in major cities.

Another variable which was significant on metropolitan level is the duration of residence. The study hypothesized that "the longer the stay, the higher the chances of eventually having housing ownership". This is an indication that staying longer in the area of residence gives female migrants an opportunity to establish good relationships with people in the neighbourhood, which could also result in the establishment of a possibility of influencing events that leads to owning a housing unit. 


\section{Non-metropolitan areas}

Looking at non-metropolitan level in Table 3, many factors contribute towards full housing ownership among female migrant compared to metropolitan areas. Age is one of the factors which play a crucial role in owning a fully paid up house. It indicates that an increase of one year in age increases the chances of owning a fully paid up dwelling unit by 1.016 times higher. Household size is significant and it increases the chances of having owned and fully paid up dwelling unit by 1.276 times higher. This means that as the household size increases, the probability of accessing full housing ownership also increases. Housing structure type is another factor which influences the likelihood of having full housing ownership in non-metropolitan areas. It clearly indicates that standalone housing units increase the chances of having full housing ownership by 2.019 times higher than staying in floating dwelling units. The reason might be that standalone housing units are much more accessible, affordable, preferable and convenient than floating housing units for female migrants heading households living in nonmetropolitan areas. However, work status decreases the chances of owning a house in non-metropolitan areas. Being paid employee, self-employed or employer female migrant reduce the chances of owning a fully paid up dwelling unit by $3.7 ; 2.36$; and 8.26 times less respectively.

Table 3 indicate further that, duration of residence is a contributing factor towards achieving full housing ownership in non-metropolitan areas. The findings show that an increase of one year of residence in an area increases the chances of having a fully owned house by 1.113 times higher. This implies that the longer the duration of stay in an area, the more the links with the people in the neighbourhood and local authorities, which increases the chances of having full housing ownership.

Table 3: Factors contributing towards housing ownership among female migrants

\begin{tabular}{|c|c|c|c|c|c|c|c|c|}
\hline \multirow[t]{2}{*}{ Independent Variables } & \multirow[b]{2}{*}{$B$} & \multicolumn{3}{|c|}{ Metropolitan areas } & \multicolumn{4}{|c|}{ Non-metropolitan } \\
\hline & & Wald & Sig. & $\operatorname{Exp}(B)$ & $\mathrm{B}$ & Wald & Sig. & $\operatorname{Exp}(B)$ \\
\hline Population group & & 2.289 & 0.515 & & & 2.019 & 0.568 & \\
\hline $\begin{array}{l}\text { Black } \\
\text { Coloured } \\
\text { Indian/Asian } \\
\text { White@ } \\
\end{array}$ & $\begin{array}{l}-0.186 \\
-0.307 \\
0.013\end{array}$ & $\begin{array}{l}1.312 \\
1.752 \\
0.002\end{array}$ & $\begin{array}{l}0.252 \\
0.186 \\
0.967\end{array}$ & $\begin{array}{l}0.83 \\
0.735 \\
1.013\end{array}$ & $\begin{array}{l}-0.11 \\
-0.24 \\
-1.3\end{array}$ & $\begin{array}{l}0.335 \\
0.938 \\
1.248\end{array}$ & $\begin{array}{l}0.563 \\
0.333 \\
0.264\end{array}$ & $\begin{array}{l}0.896 \\
0.788 \\
0.273\end{array}$ \\
\hline Age & 0.015 & 8.204 & 0.004 & 1.015 & 0.016 & 9.856 & 0.002 & 1.016 \\
\hline Household size & 0.052 & 3.145 & 0.076 & 1.054 & 0.244 & 86.986 & 0 & 1.276 \\
\hline $\begin{array}{l}\text { Marital status } \\
\text { Married } \\
\text { Not married@ }\end{array}$ & 0.17 & 1.986 & 0.159 & 1.185 & -0.02 & 0.028 & 0.868 & 0.982 \\
\hline Housing type & & 84.534 & 0 & & & 51.065 & 0 & \\
\hline $\begin{array}{l}\text { Standalone } \\
\text { Flat or block of flats } \\
\text { Floating houses@ }\end{array}$ & $\begin{array}{l}1.079 \\
0.295\end{array}$ & $\begin{array}{l}65.543 \\
2.939\end{array}$ & $\begin{array}{l}0 \\
0.086\end{array}$ & $\begin{array}{l}2.943 \\
1.343\end{array}$ & $\begin{array}{l}0.703 \\
-0.24\end{array}$ & $\begin{array}{l}35.185 \\
1.155\end{array}$ & $\begin{array}{l}0 \\
0.283\end{array}$ & $\begin{array}{l}2.019 \\
0.785\end{array}$ \\
\hline Income & & 5.575 & 0.062 & & & 12.622 & 0.002 & \\
\hline $\begin{array}{l}\text { Low income } \\
\text { Medium income } \\
\text { High income@ }\end{array}$ & $\begin{array}{l}0.56 \\
0.232\end{array}$ & $\begin{array}{l}3.273 \\
0.686\end{array}$ & $\begin{array}{l}0.07 \\
0.408\end{array}$ & $\begin{array}{l}1.751 \\
1.261\end{array}$ & $\begin{array}{l}0.643 \\
0.119\end{array}$ & $\begin{array}{l}1.448 \\
0.052\end{array}$ & $\begin{array}{l}0.229 \\
0.82\end{array}$ & $\begin{array}{l}1.901 \\
1.127\end{array}$ \\
\hline Level of education & & 1.510 & 0.47 & & & 2.364 & 0.307 & \\
\hline $\begin{array}{l}\text { Primary } \\
\text { Secondary } \\
\text { Degrees@ }\end{array}$ & $\begin{array}{l}0.142 \\
0.158\end{array}$ & $\begin{array}{l}0.532 \\
1.509\end{array}$ & $\begin{array}{l}0.466 \\
0.219\end{array}$ & $\begin{array}{l}1.152 \\
1.171\end{array}$ & $\begin{array}{l}0.143 \\
0.193\end{array}$ & $\begin{array}{l}0.856 \\
2.364\end{array}$ & $\begin{array}{l}0.355 \\
0.124\end{array}$ & $\begin{array}{l}1.154 \\
1.213\end{array}$ \\
\hline Province of previous residence & & 3.825 & 0.148 & & & 0.124 & 0.94 & \\
\hline $\begin{array}{l}\text { Urbanized } \\
\text { Not urbanized } \\
\text { Outside RSA@ } \\
\end{array}$ & $\begin{array}{l}0.419 \\
0.654\end{array}$ & $\begin{array}{l}0.716 \\
1.642\end{array}$ & $\begin{array}{l}0.397 \\
0.2\end{array}$ & $\begin{array}{l}1.521 \\
1.924\end{array}$ & $\begin{array}{l}0.169 \\
0.174\end{array}$ & $\begin{array}{l}0.116 \\
0.123\end{array}$ & $\begin{array}{l}0.733 \\
0.726\end{array}$ & $\begin{array}{l}1.184 \\
1.19\end{array}$ \\
\hline Province of birth & & 1.543 & 0.462 & & & 0.647 & 0.723 & \\
\hline $\begin{array}{l}\text { Urbanized } \\
\text { Not urbanized } \\
\text { Outside RSA@ }\end{array}$ & $\begin{array}{l}0.317 \\
0.323\end{array}$ & $\begin{array}{l}1.488 \\
1.44 \mid\end{array}$ & $\begin{array}{l}0.223 \\
0.23\end{array}$ & $\begin{array}{l}1.374 \\
1.381\end{array}$ & $\begin{array}{l}0.299 \\
0.267\end{array}$ & $\begin{array}{l}0.647 \\
0.525\end{array}$ & $\begin{array}{l}0.421 \\
0.469\end{array}$ & $\begin{array}{l}1.349 \\
1.306\end{array}$ \\
\hline
\end{tabular}




\begin{tabular}{|c|c|c|c|c|c|c|c|c|}
\hline Occupation & & 3.056 & 0.217 & & & 0.882 & 0.643 & \\
\hline $\begin{array}{l}\text { Highly skilled } \\
\text { Moderately skilled } \\
\text { Low skilled@ }\end{array}$ & $\begin{array}{l}-0.233 \\
-0.23\end{array}$ & $\begin{array}{l}2.123 \\
2.560\end{array}$ & $\begin{array}{l}0.145 \\
0.11\end{array}$ & $\begin{array}{l}0.792 \\
0.795\end{array}$ & $\begin{array}{l}-0.06 \\
-0.12\end{array}$ & $\begin{array}{l}0.194 \\
0.881\end{array}$ & $\begin{array}{l}0.659 \\
0.348\end{array}$ & $\begin{array}{l}0.938 \\
0.891\end{array}$ \\
\hline Work status & & 6.598 & 0.159 & & & 32.398 & 0 & \\
\hline $\begin{array}{l}\text { Paid employee } \\
\text { Paid family worker } \\
\text { Self-employed } \\
\text { Employer } \\
\text { Unpaid family worker }\end{array}$ & $\begin{array}{l}-0.755 \\
-0.448 \\
-0.493 \\
-1.52\end{array}$ & $\begin{array}{l}1.744 \\
0.492 \\
0.702 \\
3.171\end{array}$ & $\begin{array}{l}0.187 \\
0.483 \\
0.402 \\
0.075\end{array}$ & $\begin{array}{l}0.47 \\
0.639 \\
0.611 \\
0.219\end{array}$ & $\begin{array}{l}-1.31 \\
-0.6 \\
-0.87 \\
-2.11\end{array}$ & $\begin{array}{l}16.745 \\
2.418 \\
6.375 \\
6.420\end{array}$ & $\begin{array}{l}0 \\
0.12 \\
0.012 \\
0.011\end{array}$ & $\begin{array}{l}0.27 \\
0.548 \\
0.42 \\
0.121\end{array}$ \\
\hline Duration of residence & 0.117 & 12.098 & 0.001 & 1.124 & 0.107 & 11.705 & 0.001 & 1.113 \\
\hline Constant & -3.463 & 16.433 & 0 & 0.031 & -2.76 & 11.778 & 0.001 & 0.063 \\
\hline
\end{tabular}

Discussion of the results

Though the South African government put in place some policies which enforce housing ownership among women, such as the subsidy scheme and People's Housing Process (PHP), still there are shortcomings in the housing sector which means that many female migrants struggle to own houses. The evidence from literature has shown that there is a large demand for housing and there is a large part of the South African population that cannot afford to buy houses at market prices (Roux, 2009). Cross (2008) discovered that migrant people choose the best combination of accessibility, affordability, earnings and social environment to locate area of migration. In the following section, the variables which have an impact on housing ownership are discussed at metropolitan and non-metropolitan areas.

\section{Metropolitan areas}

In metropolitan areas of South Africa, age of female migrant was identified to be one of the contributing factors towards owning a fully paid up house. This study reveals that, with an increase in age of female migrants, the chances of accessing owned and fully paid up houses also increases. This implies that young female migrants who head households are predominantly living in rented housing units, but as they become older, the tendency is to buy own house (Malpezzloping, 1989, UNCHS, 2003; and Dewandeler, 2006).

In fact, these findings was consistent with what is in existing literature since it is commonly known that it takes time to accumulate enough income and wealth to buy a place to stay. Bank repayments for the housing bond takes quite many years to complete. Furthermore, for those who have access to government housing schemes, they can stay for a long time on waiting list for them to benefit on the RDP housing scheme, People's Housing Process scheme or the Breaking New Ground Housing scheme (Landau, Segatti, and Misago, 20I I).
Household size was also observed to be an important factor that increases the likelihood of living in owned and fully paid up housing unit. In fact, small households are most likely to live in rented housing and often move to new areas of residence than large households. Yet, large households often appear to stay in big houses which are often owned and fully paid up. This implies that as the household grows larger, there is often a need and pressure to purchase own housing unit to accommodate that large family (Kabajuni, 2009).

Duration of residence was also thought to be an important factor which contributes to the propensity to acquire an owned and fully paid up house for female migrants living in metropolitan areas. This confirms the hypothesis that, the longer the stay in area of residence, the more female migrants become familiar to the neighbourhood and information on financial institutions' facilitation to purchase a housing property. Moreover, staying a long time in a place increases the familiarity with the environment, learn about housing institution in the area and all financing facilities and this eases housing ownership (Udjo and Lalthapersad-Pillay, 20I5).

\section{Non-metropolitan areas}

In non-metropolitan areas, the result shows that age, household size, housing structure type, work status and duration of residence all facilitate the likelihood of acquiring full housing ownership for female migrants living in non-metropolitan areas, while work status reduces the possibilities of acquiring housing ownership. An increase in age was observed to play a crucial role in increasing the chances of accessing an owned and fully paid up dwelling unit. In reality, this might be true in the sense that as female migrant grow older; she strives to own a place to stay permanently, at least to have secure retirement home and inheritance to children. Household size also plays a crucial role in increasing the propensity to access owned and fully paid up house in non- 
metropolitan areas. In these medium sized and small towns, extended families are prominent and it creates the need to own bigger space to stay in. Therefore, household size increases the likelihood of housing ownership among female migrants living in non-metropolitan areas.

Household structure type, especially standalone housing type, fuels the propensity to access owned and fully paid up dwelling unit in non-metropolitan areas. This is not surprising because in nonmetropolitan areas, people are likely to stay in standalone housing units than in flats or in floating dwelling units (Schnaiberg, 1970). This is relevant in a sense that free standing houses are common in those areas falling outside metropolitan areas. Duration of residence was also observed to boost the possibility of acquiring owned and fully paid up dwelling unit among female migrants living in non-metropolitan areas. These findings are in general agreement with what exists in literature which states that the duration of residence is associated with better housing conditions, including security of housing tenure (Huq-Hussain, 1996).

Work status was identified to be a risk factor for housing ownership in non-metropolitan areas. As the South African government strives to empower poor women through provision of governmental housing (Charlton, 2004), this study found that being employee, self-employed or employer does not necessarily entitle female migrants living in medium or smaller towns on full housing ownership. In South Africa, it takes about 30 years to repay a housing loan bond.

\section{Conclusion}

The main focus of this study was female migration and housing acquisition in South Africa. It looked at the magnitude and the direction of female migrants in South Africa. The main objective was to examine the relationship between female migration and housing ownership across metropolitan and non-metropolitan areas of South Africa. The study found that female migrants are more likely to move to the areas of high economic opportunities, especially in large cities. Hence, housing ownership of female migrants is prominent in non-metropolitan areas as a result of less housing competition observed in those areas. This is an indication that female migrants living in metropolitan areas use methods of housing acquisition other than housing ownership. They rather opt for renting. In general, factors such as age, housing type, and duration of residence increase the chances of having housing ownership among female migrants regardless of areas of residence. Household size is an influential factor that increases the chances of having housing ownership among female migrants http://aps.journals.ac.za living in non-metropolitan areas, while on metropolitan level, however, this variable was not relevant.

\section{Recommendation}

Given that housing in metropolitan areas are almost unaffordable for female migrants, government housing schemes and non-profit organisations should prioritise female migrants. The government in delivering low cost housing (social housing), Reconstruction and Development Programme, or site and service programmes should consider the needs and priorities of female migrants in terms of site design and nature of infrastructure and service provision that meet their needs. Even though the National Department of Housing could count some success in the area of reaching female headedhouseholds as beneficiaries of housing subsidy programmes, discrimination of female migrants in workplaces still a barrier to housing ownership. Women are, mostly, still held in subordinate positions with low wage, and with low access to government assets. Therefore, exclusion of women through eligibility criteria should be discouraged, and methods of beneficiary recruitment should be revised in favour of female migrants. Gender dimensions to renting and gender related constraints to owner-occupation should also be amended. Future research among female migrants and non-migrants in the context of South Africa is needed to elaborate on the differentials. This should be done using fresh migration data set to explore the current situation of female migration and housing in South Africa.

\section{References}

Beyene, J., 2005. Women, Migration and the household: The case study of three households of Ethiopian and Eritrean female migrant workers in Beirut and Naba'a. Ph.D, American University of Beirut.

Browne, C. V. and Braun, K. L., 2008. Globalization, women's migration, and the long-term-care workforce. The Gerontologist. 48(I), pp. 16-24.

Charlton, S., 2004. An overview of the housing policy and debates, particularly in relation to women (or vunerable groupings). Johannesburg: University of the Witwatersrand.

Cross, C., 2008. Housing delivery as anti-poverty: Is South Africa on the right track. Southern African Housing Foundation International Conference, pp I2-15.

Curran, S.R. and Rivero-Fuentes, E., 2003. Engendering migrant networks: The case of Mexican migration. Demography, 40(2), pp. 289307. 
Dewandeler, K., 2006. A Quick guide on rental housing. UNESCAP/UN-Habitat.

Fawcett, J.T., Khoo, S. E and Smith, P.C., 1984. Women in the cities of Asia. Migration and urban adaptation. Westview Press, Inc., United States.

Feliciano, C., 2005. Does selective migration matter? Explaining ethnic disparities in educational attainment among immigrants' childrenl. International Migration Review, 39(4), pp.84I871.

Fisher, L.M., and Jaffe, A.J., 2003. Determinants of international home ownership rates, working paper.

Gardner, D. A. V. I. D., 2004. Sharpening the Focus: A New Look at South Africa's Housing Strategy. Housing Finance Resource Programme.

Groenmeyer, S., 2010. Living in the Shadow of the Moon: Approaches to Women and Migration in Contemporary Post-Apartheid South Africa

Huang, Y. and Clark, W.A., 2002. Housing tenure choice in transitional urban China: A multilevel analysis. Urban Studies 39 (I), pp. 7-32.

Huq-Hussain, S., 1996. Female migrants in an urban setting: The dimensions of spatial/physical adaptation: The case of Dhaka. Habitat international, 20(I), pp. 93-I07.

Ingram, G. K., 1997. Patterns of metropolitan development: what have we learned? (No. I84I). World Bank Publications.

Ingram, G. K., 1998. Patterns of metropolitan development: what have we learned? Urban studies, 35(7), pp. I019-1035.

Kabajuni, A., 2009. Urbanisation and gender: Attention to gender equality in efforts to improve the lives of slum dwellers (COHRE). New York, United Nations.

Lee, E. S., 1966. A theory of migration. Demography, 3(I), pp.47-57.

Landau, L. B., Segatti, A. and Misago, J. P., $201 \mathrm{I}$. Governing Migration and Urbanisation in South African Municipalities: Developing Approaches to Counter Poverty and Social Fragmentation. South African Local Government Association: Pretoria.

Lekoa, M., 20ll. Migration into New Housing Developments: An Examination of RDP Housing in Northern KwaZulu-Natal. Doctoral dissertation, University of KwaZulu-Natal, Durban.

Malpezzloping, S., 1989. Rental housing in developing countries. Issue and constraints, unpublished paper.

Maharaj, J. R., 2012. The effect of good working capital policy on exploiting the fiscal capacity of municipalities in Kwazulu Natal .Ph.D, University of South Africa.
Miraftab, F., 1996. Space, gender and work: Homebased workers in Mexico. Homeworkers in Global Perspective: Invisible no More, pp. 63-80.

Miraftab, F., 2003. The Peril of participatory discourse: Housing policy in post-apartheid South Africa. Journal of Planning Education and Research, 22:226-239.

Obaid, T. A., 2006. State of world population 2006. UNFPA.

Adeomene, A, and Osuji, O., 2015. Nurses's International Migration and the Crystallizing Culture of Exile in Nigeria: Historical Trends, Dynamics and Consequences. African Population Journal, Vol 29, No.I

Roux, N., 2009. Migration and Urbanisation-Towards a 10-year review of the population policy implementation in South Africa (1998-2008). Department of Social Development, March 2009.

Rust, K., 2006. Analysis of South Africa's housing sector performance. FinMark Trust, December 2006.

Shaw,R.P., 1976. Migration theory and fact. Bibliography series, 5, Philadelphia; Regional Science Research Institute.

Schnaiberg, A., 1970. Rural-Urban residence and modernism: A study of Ankara province, Turkey. Demography, 7(I), pp.7I-85.

Statistics South Africa, 2003. Investigating into appropriate definitions of urban and rural areas for South Africa. Discussion document. Report No 03-02 (200I). Pretoria: Statistics South Africa.

Swart, E. C., 2004. The Effects of Internal Migration and Related Factors on Nutrient Intake and Anthropometric Status of Children Aged I-9 Years in South Africa, 1999. Ph.D. University of the Western Cape.

Tati, G., 2008. Research Methodology. Principles and Steps in Research Process. Bellville: University of the Western Cape.

Udjo, E.O. 20I5. Projecting population, numbers of households and dwelling units in South Africa 201 I - 20I2. African Population Studies, Vol. 29, N.I

Udjo., E and Lalthapersad-Pillay., 2015. Assessing the achievements of Millennium Development Goals in Southern Africa. African Population Studies Journal, Vol.29, N0.I.

UNCHS, 2003. Rental housing: An essential option for the urban poor in developing countries, Nairobi.

White Paper, 1994. A New Housing Policy and Strategy for South Africa. [online] Available at: <http://www.info.gov.za/whitepapers/ I994/housi ng.htm/> [Accessed 23 October 20I2]. 